\title{
Ten thousand years of climate change
}

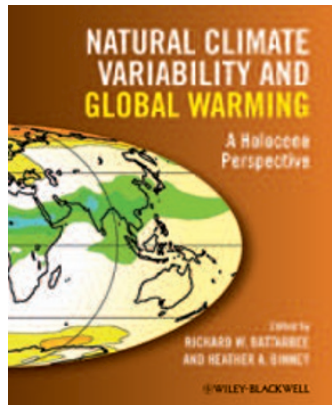

The proceedings of the 2006 meeting on Holocene climate variability (HOLIVAR) explore climate change over the past 10,000 years and reflect the deep transformations in the field over recent decades. The volume brings together an interdisciplinary group of European palaeoclimatologists, with a scientific focus on Europe and North Africa that nevertheless represents a diverse collection of perspectives and approaches to palaeoclimate research. A bird's eye view of Holocene climate research reveals a movement away from poorly dated and low-resolution archives to absolutely dated and high-resolution records.

The latter types of data can be calibrated against the instrumental record, combined into syntheses of regional and/or global climate, and compared directly to climate model outputs. Nowhere is this transition more apparent than in Europe, where palaeoscientists have laboured for the better part of a century to extract qualitative information on past climates from Europe's numerous lakes, peat bogs and glaciers. Therefore, it is not surprising that the Euro-centric HOLIVAR volume bundles remnants of palaeoclimate's history together with some exciting glimpses of its future, sometimes in the same chapter.

Global climate models provide a wide range of projections for the twenty-first century, and climate research is focused on reducing these ranges and uncertainties. The use of palaeoclimate data that provide a longer view of climate change than is available from the 150-year-old instrumental record can help to distinguish natural from anthropogenic climate variability and to determine the response of the climate system to specific forcings, whether natural or anthropogenic. Palaeoclimatologists have long focused on the Holocene - the current interglacial period - for such work because global climate boundary conditions were broadly similar to those of today. Identifying those aspects of the Earth's climate system that are sensitive to natural climate forcing and understanding the causes and consequences of climatic extremes can help to assess society's vulnerability to such events under continued climate change.

Early chapters of the book paint European Holocene palaeoclimate research in broad, historically tinted brush strokes, sprinkled with some tantalizing discussions of the interactions between climate change, human history and ecosystem response. In one chapter, Frank Oldfield argues convincingly that the Holocene holds untold lessons for our modern-day concerns about how land-use changes affect regional climate responses, and in turn, how society will be affected by climate change. Although these chapters are colourful and intriguing, their ties to global warming uncertainties are indirect at best.

Eystein Jansen and colleagues present a detailed investigation of the signature of the 'Holocene Thermal Optimum' in the North Atlantic. Indeed, the chapter presents new twists on an old and somewhat ambiguous story. Unfortunately, the authors do not explain the implications of this palaeoclimatic feature for present-day climate change.

Whether or not changes in solar irradiance have a significant effect on Earth's climate is still hotly debated, as conceded in Jürg Beer and Bas Van Geel's chapter. Using a provocative portfolio of palaeo-evidence, they argue that the Sun's influence is readily detectable in the palaeoclimatic record. It is a rousing presentation, although they fail to address some of the most problematic new developments for solar-climate enthusiasts, some of which are touched on in later chapters.

The last four chapters of the book provide exhilarating previews into the future of palaeoclimate studies and illustrate how palaeoclimate data can be important in reducing the uncertainties surrounding future climate projections and impacts. These are the chapters that delineate the big challenges and potentially huge payoffs that every palaeoclimate-oriented graduate student should internalize.

From the maturity of multi-proxy reconstructions and simulations of the last millennium's climate, to the relatively 'Sci-Fi' world of palaeoclimate data assimilation, Hugues Goosse and colleagues use a rigorous, quantitative and well-reproduced set of results as the inspiration for techniques that closely integrate palaeoclimate data with dynamic models.

Many would argue that changes in regional hydrology are the largest potential impacts of climate change; yet they represent one of the greatest uncertainties in climate models. Ray Bradley illustrates eloquently and passionately how palaeoclimate data can be used to probe the causes and consequences of so-called AUP (abrupt, unprecedented and persistent) droughts and other hydrological extremes evident in many high-quality palaeoclimate data sets. However, Dirk Verschuren and Dan Charman illustrate the challenge of extracting quantitative information about regional water balance from a diverse array of palaeo-hydrological indicators. Martin Claussen's chapter on the interactions between climate and ecosystem changes seamlessly blends palaeoclimate evidence with pressing modern-day concerns about the future of our environment.

Natural Climate Variability and Global Warming: A Holocene Perspective is a meandering tour of European Holocene palaeoclimate research. Those chapters that rise to the challenge of the book's title represent the elegance and immense promise of recent palaeoclimatic records and techniques.

Kim M. Cobb

Kim Cobb is in the School of Earth and Atmospheric Sciences, Georgia Institute of Technology, MC 0340, 311 Ferst Drive, Atlanta, Georgia 30332-0340, USA. e-mail: kcobb@eas.gatech.edu 